\title{
Julius Margolin, Voyage au pays des Ze-Ka
}

Paris, Éd. Le Bruit du temps, 2010

\section{Tanguy Wuillème}

\section{(2) OpenEdition}

\section{Journals}

Édition électronique

URL : http://journals.openedition.org/questionsdecommunication/2803

DOI : 10.4000/questionsdecommunication.2803

ISSN : 2259-8901

\section{Éditeur}

Presses universitaires de Lorraine

\section{Édition imprimée}

Date de publication : 30 juin 2011

Pagination : 337-340

ISBN : 978-2-8143-0084-2

ISSN : $1633-5961$

\section{Référence électronique}

Tanguy Wuillème, "Julius Margolin, Voyage au pays des Ze-Ka », Questions de communication [En ligne], 19 | 2011, mis en ligne le, consulté le 22 septembre 2020. URL : http://journals.openedition.org/ questionsdecommunication/2803; DOI : https://doi.org/10.4000/questionsdecommunication.2803

Ce document a été généré automatiquement le 22 septembre 2020.

Tous droits réservés 


\section{Julius Margolin, Voyage au pays des $\mathrm{Ze}-\mathrm{Ka}$}

Paris, Éd. Le Bruit du temps, 2010

Tanguy Wuillème

\section{RÉFÉRENCE}

Julius Margolin, Voyage au pays des Ze-Ka, Paris, Éd. Le Bruit du temps, 2010, 782 p.

1 Voyage au pays des Ze-Ka

2 Nous n'ignorons plus la part absurde et ignoble des camps de redressement de l'URss mis en place dès Lénine, surtout consolidés en juin 1929, quelques mois avant le Grand Tournant et qui devaient perdurer au-delà même de son principal instigateur, Staline. Ce sont des millions de morts abandonnés à la faim, à la maladie, à la fatigue extrême afin de normaliser toute une société et de réduire en esclavage ceux jugés comme déviants. Seulement voilà. Cette mémoire souffre encore d'un manque de visibilité (comparée à celle de l'extermination organisée par les nazis) et de lisibilité, même si les ouvrages de Varlam Chalamov, de Margarete Buber-Neumann ou d'Alexandre Soljenitsyne en sont des témoignages incontournables.

La raison en est éditoriale, comme en atteste cette première publication enfin complète d'un des premiers grands récits de l'enfermement généralisé, celui du polonais Julius Margolin, publié en 1947. Au moment où, dans les chapelles intellectuelles, fleurissent des expressions comme "l'hypothèse communiste", où existent des partis qui en portent le nom, où l'on peut arborer sur soi ou chez soi des signes de l'esthétique soviétique, il s'agit d'abandonner toute nostalgie mélodramatique de la politique communiste. Le mot est devenu sale et injurieux pour tous ceux qui ont vu leur dignité et leur humanité bafouées en son nom. Le livre de Julius Margolin est un livre édifiant, non par la gravité du sujet (cela suffirait en soi) mais du fait de la ténacité qui s'y trouve. C'est un récit de survivant, il cherche à tout garder en vie. Il raconte comment l'on rentre arbitrairement et comment l'on sort miraculeusement d'une détention de 
cinq ans (1940-1945). La longueur du livre est à la mesure de l'épreuve, du temps long qu'est le rythme imposé par le pouvoir et l'administration soviétique. On sent une vraie frénésie à tout relater, à détailler l'absurdité du mécanisme administratif : de la nondétention des papiers d'identité dans une Pologne que vont se partager d'un commun accord les soviétiques et les nazis, au statut d'une existence illégale, aggravée par le fait d'être juif et de résider à l'époque en Palestine. Julius Margolin était venu voir ses parents en Pologne, quand il ne put en sortir et repasser la frontière. Il devient apatride, extérieur, donc suspect et dangereux. De plus, il porte des lunettes d'intellectuels (il est docteur en philosophie). Il décrit comment, du jour au lendemain, il se transforme en travailleur soviétique. Le travail est le critère de sélection et d'organisation de ce monde nouveau, il le sera dans les zones occupées et plus encore dans les camps. Le récit de Julius Margolin se découpe en deux parties, la première qui permet d'apprécier son existence kafkaïenne dans une Pologne encore cosmopolite mais occupée, la seconde qui relate son expérience d'interné. La seconde est la plus importante et la plus consternante. Il s'agit en premier lieu d'une description de la condition de prisonnier et du fonctionnement des institutions coercitives soviétiques. Le Goulag - qui enfermera vingt millions de personnes sous Staline, en déportera sept millions et fera deux millions de morts - consiste à faire travailler les détenus purgeant une peine d'emprisonnement supérieure à trois ans. On y voit une hiérarchie, des rôles bien spécifiques, des corruptions en tous genres chez des fonctionnaires et des gardiens eux-mêmes punis. Les règlements y sont omniprésents, mesquins. La statistique rassure tous les soucieux de la rentabilité, l'évaluation cherche à définir des degrés de bons et mauvais travailleurs. Rien ne résiste à ce rouleau compresseur de l'organisation rationnelle qui semble avoir tout le temps devant lui alors que celui des individus est compté et précieux.

4 Julius Margolin montre avec finesse la peur du chef, du chiffre non fait, des commandements non appliqués. Tous les fonctionnements de la bureaucratie comportent leur contrepartie psychologique, l'ennui, la paralysie, le cynisme. Résultat : le travail est bâclé, inutile et destructeur de vies humaines. Il s'agit de la plus vaste entreprise d'esclavage mis au monde aboutissant à un fiasco économique (on sait que le canal Baltique-mer Blanche, où Julius Margolin est affecté, sera inapproprié aux bateaux). La condition du Ze-Ka est décrite par Julius Margolin comme celle d'une déshumanisation progressive. Le chapitre XIII du livre contient les analyses les plus impressionnantes de ce processus de dégradation de la vie humaine. Il existe une logique générale : l'individu est conduit à se considérer comme un rebut. Plus rien ne témoigne pour lui, il n'a plus d'identité, de famille, de patrie, n'a plus de métier ni de rang social. Il doit être vide et transparent, étant donné qu'il est placé sous la surveillance omniprésente de tout un chacun (surtout de ses congénères). Il est exigé de lui un travail surhumain (sans outils ou du moins défaillants) dans des conditions extrêmement pénibles (réveil à l'aube, climat polaire, cadence infernale). Mais l'obsession première du camp est la faim. Il semble qu'il n'y ait pas un chapitre du livre qui ne relate la souffrance due à l'absence de pain, de soupe, de ration suffisante, ce qui engendre la rapine, la dissimulation, la violence. La guerre civile est à l'intérieur du camp, comme elle était présente dans toute l'uRss (campagnes/villes, nomenklatura/ classes moyennes). Aucun interné n'ose se confier, se défendre ou résister car tout peut être un moment ou l'autre utilisé contre lui. La déchéance est donc autant physique (il perd $35 \mathrm{~kg}$ en cinq ans, vit sous des guenilles, se couvre de furoncles, a des ulcères, etc.) que morale. Il voit la mort progresser tout autour de lui, apprend celle des siens à 
distance. L'attachement amical se paie cher. Un sentiment d'impuissance gagne chacune des âmes, on retrouve la honte analysée par Primo Levi, le retour à la vie animale, nue, muette, passive, résignée à la mort qui délivre.

Julius Margolin décrit ces êtres-déchets: les "dokhodiagui» (sorte d'équivalent des «musulmans » d'Auschwitz), on le perçoit « lorsqu'un détenu descend au-dessous de ce minimum physique ou moral, qui lui permet de se maintenir à la surface de la vie du camp » (p. 268). Rien ne nous est épargné de ce communisme de la pauvreté, de la saleté, du mensonge généralisé, de la cruauté. La dépersonnification n'y est pas hasardeuse mais délibérée. Il s'agit d'un monde à l'envers où les valeurs irrationnelles l'emportent. L'auteur va cependant tenter de sauver ces petites vies ordinaires, minuscules, de l'anonymat. Les portraits qu'il fait de ses camarades (mot pourtant imprononçable dans les camps) sont touchants et évocateurs de ce que le système est en train de briser. L'écriture devient messianique, revancharde, tout emplie d'une tristesse colérique. Elle est un moyen de conjurer le malheur, d'espérer que ces visages d'origine, de couleur et de talent si divers, que ces noms rayonnent un peu plus dans l'avenir. Tout le livre est un plaidoyer pour en finir avec l'oubli et la dénégation. Ceux des contemporains (en 1947) et ceux qui viendront après. Julius Margolin ne cesse de constater l'inanité et la fausseté de la poésie politique, de ceux qui chantaient encore Staline et la grandeur du pays des Soviets. Dans l'article situé en fin d'ouvrage, Luba Jurgenson, qui a revu la traduction initiale de Nina Berberova et de Mina Journot, revient sur la difficulté de Julius Margolin à défendre David Rousset lors de son procès en 1950. Les Lettres Françaises, la grande revue littéraire des communistes accusait celuici de mensonge. David Rousset fait venir à la barre les rescapés des camps staliniens pour contrer les accusateurs, Pierre Daix, Joë Nordmann, qui tentent eux d'empêcher les déposants de se faire entendre.

6 Pour prolonger et dépasser la réflexion de Luba Jurgenson, il faut lire les autobiographies de personnalités staliniennes françaises, celle précisément de Pierre Daix (J'ai cru au matin, Paris, R. Laffont, 1976) et de Joë Nordmann (Aux vents de l'histoire, Aix-en-Provence, Actes Sud, 1996) car ils y avouent (trente ou cinquante ans après) leur aveuglement, leur manque d'esprit critique quant au déni de croire en l'existence de la Kolyma. Cependant, on les voit se justifier constamment et tout un rapport à la vérité se dévoile : ils déclarent avoir été vrais avec eux-mêmes, avoir eu de bonnes raisons de croire, ils ne cessent de contextualiser leurs positions de l'époque qu'ils replacent dans une configuration agonistique, affirmant qu'alors les camps ne pouvaient être qu'une rumeur. Ils ont diffamé Victor Kravchenko, David Rousset, Margarete Buber-Neumann, ils n'ont vu dans leurs récits de détention qu'une propagande propre à l'entreprise américaine. Le croyant post-stalinien, même tardivement averti, persiste et signe à croire que la vérité politique et historique doit toujours être relativisée en fonction d'un espace de lutte des opinions. Le livre de Julius Margolin pose effectivement la question fâcheuse du communisme au $\mathrm{XX}^{\mathrm{e}}$ siècle. Une volonté d'égalité des êtres entre eux qui contribue à extirper toute différence, toute originalité.

7 L'État communiste, fondé sur la connaissance et la maîtrise des lois de l'Histoire, se croit en droit d'éliminer sans pitié tous ses ennemis et d'araser les têtes qui dépassent selon la logique implacable de la «lutte des classes». Julius Margolin rend concrets et vivants ces paysans qui se sont opposés à la collectivisation (koulaks exploiteurs), ces ouvriers qui ont refusé la course à la productivité (devenant ainsi des «saboteurs»), ces petits entrepreneurs et artisans que l'on traitait « d'éléments déclassés ». Il voit 
comment on les a réduits au conformisme, à l'obéissance. Il montre comment la propagande omniprésente même dans les camps sous forme de pancartes, de banderoles, d'affiches auxquelles plus personne ne prêtait attention, inoculait le virus de l'inexistence et de l'idéologie absurde. L'antisémitisme, l'anti-intellectualisme étaient de rigueur. On trouve d'ailleurs des analyses passionnantes sur ces deux pathologies partagées par la population soviétique et prisonnière. On leur attribue tous les maux de la Russie : les juifs sont des révolutionnaires qui cherchent à se distinguer, les intellectuels sont les instigateurs des Soviets. Julius Margolin est empêché de lire par ses congénères, « la haine du régime, qui ne trouve aucune forme d'extériorisation politique, s'est muée en haine contre les intellectuels en général de qui viennent tous leurs tourments. La masse inculte en Russie ne connaît aucune "intelligentsia », aucun livre, aucune science, aucune idéologie autres que communistes. L'aversion sourde et violente pour cette idéologie, l'indifférence et le mépris pour toutes les autres, ont gagné toutes les classes de la population, se sont répandues sur un sixième du globe » (p. 510).

8 Julius Margolin cherche à comprendre la logique du désastre de la détention, qu'il ne veut pas rapporter uniquement à son cas personnel. Il voit que ces événements ne sont pas une erreur du système, qu'il ne s'agit pas de "redresser» des êtres autrefois courbés sous l'obéissance tsariste. Les camps sont pour le régime communiste une nécessité historique, un moyen de damer le pion aux puissances dites capitalistes et occidentales en érigeant le travail obligatoire en valeur. Pour cela l'esclavage est le meilleur moyen d'égaliser tout le monde. «Il ne saurait y avoir de communisme à l'échelle nationale sans un pouvoir central dur qui réalise le plan économique par des mesures coercitives. Or, il n'y a pas de communisme sans planification, pas de planification sans travail contraint, pas de travail forcé sans les camps» (p.586). L'auteur aide également à comprendre la différence entre les camps nazis et soviétiques : l'extermination y était moins rapide, le martyr plus long voire éternel. Dans les camps allemands, on devient immédiatement fou lorsque la fille se fait tuer sous les yeux de la mère ; dans les camps soviétiques, « on ne connaît pas ces horreurs [...] ils sont peuplés d'hommes qui, extérieurement, semblent normaux; mais à l'intérieur, ils ne sont que plaie ouverte. Ils ne pleurent pas, ils ne protestent pas; s'ils pouvaient le faire, ils seraient encore normaux. Mais ces gens ne sont plus capables de comprendre ce qui se passe dans le monde, dans le camp, dans leur âme» (p. 551). La destruction des âmes y est tout autant inédite. Lire ce type de récits a plusieurs vertus : celle d'apprendre à connaître le malheur et d'apprécier la chance d'y échapper : un bon repas, une bonne douche, un lit propre suffisent à rendre heureux. Cela permet en retour de reconnaître le désir d'améliorer sa condition qui a prévalu en Europe après 1945 et l'idéal de la social-démocratie. L'ouvrage renseigne sur les raisons de la lenteur de la sortie du communisme, sur l'impact de la traduction, de l'interprétation, de la compréhension de ce qui se jouait dans ses souterrains de l'Eurasie. Comment croire à ce qui était caché, censuré, dénié, il était plus facile de s'en remettre aux initiales vérités dogmatiques. La minutie avec laquelle Julius Margolin analyse la sociologie du camp et la psychologie des hommes fournit un formidable tableau de la condition (in)humaine : la bonté et la malignité s'y trouvent à égalité, les circonstances éliminent la première. La haine devient le sentiment premier et l'auteur amorce une réflexion construite sur celle-ci, elle unit les hommes, constitue une force active et puissante. Le communisme apparaît comme le fascisme et le nazisme, une usine à entretenir la haine. «Les hommes qui, à l'été 1940, ont brisé ma vie et m'ont transformé en esclave ne me 
connaissaient pas ; moi non plus, je ne les connaissais pas. Mais, entre eux et moi, la Haine se dressa. Ce n'était pas une haine personnelle mais un phénomène collectif, né avec notre époque, un produit lénino-stalinien, un poison abstrait qui s'infiltra dans le sang et dans la chair de toute une génération " (p. 613). La haine consiste à ne pas vouloir connaître l'autre, à colporter les rumeurs, les stéréotypes, les clichés, elle semble là pour guetter les moindres faiblesses, erreurs ou péchés. Pour ne prendre que cette donnée, on voit combien le livre de Julius Margolin est précieux pour lire certains des agissements contemporains du système médiatique et de toute collectivité humaine.

\section{AUTEURS}

\section{TANGUY WUILLÈME}

CREM, université Nancy 2

tanguy.wuilleme@univ-nancy2.fr 